\title{
The number of false mounting affects the quality of semen in bulls
}

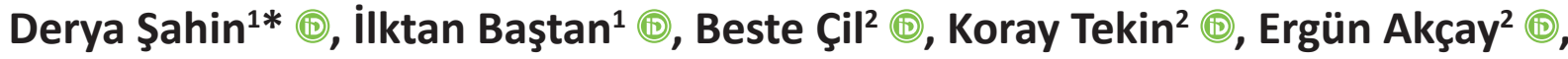 \\ Ali Daşkın² (0), Calogero Stelletta ${ }^{3}$ (5)
}

\author{
${ }^{1}$ Department of Biotechnology, International Center for Livestock Research and Training, Ankara, Turkey \\ ${ }^{2}$ Department of Reproduction and Artificial Insemination, Faculty of Veterinary Medicine, Ankara University, Ankara, Turkey \\ ${ }^{3}$ Department of Animal Medicine, Productions and Health, University of Padova, Padova, Italy.
}

\section{Article History \\ Received: 07 March 2020 \\ Accepted: 20 July 2020 \\ *Corresponding Author \\ vh.sahinderya@outlook.com}

\section{Key words}

Cryopreservation, false mounting, freezability, libido, bull, sexual preparation

\begin{abstract}
Bulls in Artificial Insemination (Al) Centres are generally trained with false mounting (FM) activity in order to improve the quality of semen. 360 ejaculates were collected via artificial vagina from twelve bulls. The bulls were subjected to each group according to the number of FM activity (FM- 0 , FM- 1, and FM- 2). After the initial examination, samples were diluted and were frozen using a digital freezing machine. Post-thaw quality of sperm was assessed by using a computer assisted sperm analyzer and a photometer. Significant differences were obtained among the FM groups regarding the volume and concentration $(P<0.001)$. The highest concentration was obtained in FM- 2 group as $1326.7 \pm 365.07 \times 10^{6}$ sperm/ $\mathrm{mL}(\mathrm{P}<0.001)$ and the number of straws produced per ejaculate was highest in FM2 group $(P<0.05)$. Individual responses of the bulls to $F M$ activity have revealed that, in general, double FM resulted in improved post-thaw motility and therefore the freezability $(P<0.001)$. In conclusion, in this study aimed to evaluate the relationship between the number of FM and sperm quality, double FM is a practical method for increasing the sperm output and post-thaw motility of the insemination doses produced in Al Centres.
\end{abstract}

\section{Introduction}

Duct of epididymis, ductus deferens and ampulla are the extragonadal sites of sperm reservoirs in the male genital tract, although, during the ejaculation, only a part of sperm reserved in the tail can be expulsed. In order to maximize the output of spermatozoa per ejaculate, sexual preparation plays a key role and can be achieved by extending the period of sexual stimulation beyond what is needed for mounting and ejaculation [5, 31]. Sexual preparation starts with the sensory stimulation via optic, olfactory, tactile and auditory stimulus, followed by the stimulation of the nerves in the supraoptic and paraventricular nuclei, which leads to the release of oxytocin from posterior pituitary that can cause the contractions of smooth muscle in the distal tail of epididymis and ductus deferens, thereby the transport of spermatozoa into an ejaculatory position. Steroids, especially testosterone is the main hormone that is responsible for the regulation of sexual behaviors. While the sexual behavior was reduced in orchiectomized males, exogenous testosterone or $E_{2}$ resulted with the restored sexual behavior [31].
The relationship between sexual behavior and semen quality mirrors the reproductive efficiency of stud bulls and has a significant importance in the breeding program, particularly in the selection criteria of bulls and the decisions of the suitable management interventions in order to optimize the production performance individually. Besides, initial semen quality has an important effect on the post-thaw spermatological parameters as well. Even with the most suitable protocol of cryopreservation, approximately half of the sperm population may lose their ability of motion due to freezing and thawing process. Thus, the initial concentration of sperm and their tolerance against the detrimental effects of cryopreservation process are essential for a profitable management in Artificial Insemination (AI) Centres. In order to achieve the highest sperm output during the routine semen collections, males are sexually prepared by three approaches, which can be listed as false mounting (FM), restraint, and the combination of these two methods [15]. For the efficiency of the restraint method, it is important to distinguish between the actual stimulation of the bull and simply its standing position close to 
the stimulus animal. However, this assessment can be subjective. On the contrary, FM is always recommended since it is evident to the observer [8]. In general, bulls are initially trained with FM (allowing the bull to mount, but not to ejaculate) on a teaser animal and are afterwards restrained on the teaser for several minutes to maximize their sexual stimulation and sperm quality. FM consists of manually deviating the penis during a mount so that intromission and ejaculation cannot occur. Restraint prevents the male from mounting even though he wishes to do so. Generally, restraint is for two to three minutes within half to one meter of the stimulus animal. In dairy bulls, the recommended procedures for sexual preparation are: one false mount followed by two minutes of restraint, followed by two additional false mounts before each ejaculation [9, 18, 31]. Although some researches have tested the effect of three FM and collecting the semen on the fourth attempt, this approach was found highly risky due to concerns of animal welfare since animals were more prone to get injured during the increased numbers of mounting attempts and dismounting $[5,13,30]$. It has been suggested that with the method of sexual stimulation and/or preparation, increased motility, sperm survival and conception rates could be obtained $[3,9]$. It has been noted that sexual preparation is more effective in dairy than beef bulls [3, 9]. However, the studies are mainly conducted in the 1950s. Thus, it would be useful to determine whether these findings are applicable for use in current technology for semen collection and examination [24]. Therefore, in the present study, evaluation of the relationship between the number of FM and sperm quality of fresh and cryopreserved bull semen was aimed.

\section{Materials and methods}

\section{Animals}

Semen samples were collected from twelve fertility proven bulls ( 2 - 4 years of age) of three different breeds (6 Simmental, 5 Brown Swiss and 1 Holstein) which are kept under a uniform diet program and housing conditions in the Lalahan International Livestock Research Institute (Ankara, Turkey). These bulls are on a regular collection schedule for semen production and had fulfilled a standard breeding soundness evaluation as well as requirements of routine disease-control.

\section{Experimental design}

On each collection date, bulls were assigned to three groups (FM- 0, FM- 1, FM- 2) regarding the number of FM, and all the animals were subjected to manipulations of each group with five repetitions. FM- 0; semen collection was completed on the first mount attempt of the bull, without false mounting. FM- 1; semen was collected on the second attempt of mounting, following the first false mounting. FM- 2; semen was collected on the third attempt of mounting, after the bulls were false mounted twice. Sexual preparation of the bulls was achieved by keeping the animal restrained for 3 to 5 minutes between the mounting activities. The semen was collected during a maximum of third attempt in order to reduce the risk of injuries of the bulls.

\section{Collection, cryopreservation and evaluation of semen}

Ejaculates $(n=360)$ were collected on two days weekly by using an artificial vagina with the presence of a teaser animal. On each collection date, ejaculates were collected twice, consecutively, from the same bull, 5 minutes apart and the same FM procedure was applied prior to each collection. Consecutive ejaculates collected on the same day, that belonged to same animals were pooled and examined initially taking into account the volume, concentration using a photometer (Accucell, IMV, France) and motility using a phase contrast microscope [12].

A commercial semen extender (Andromed, Minitüb, Germany) was used to dilute the semen. After three hours of an equilibration period at a temperature of $4{ }^{\circ} \mathrm{C}$, cooled aliquots were loaded into $0.25 \mathrm{~mL}$ French straws with a final ratio of $20 \times 10^{6}$ spermatozoa / straw. Straws were frozen using a digital freezing machine (Digitcool 5300 ZB 250, IMV, France) program and maintained in liquid nitrogen at least for one month until further analysis.

The straws were thawed in a $37^{\circ} \mathrm{C}$ water bath for 30 s. Total motility and progressivity were assessed by using IVOS I CASA individual software (Hamilton Thorne Inc., Beverly, USA) with the existing species-specific evaluation parameters for bulls. In the analysis settings, spermatozoa with VSL 70\% and VAP $50 \mu \mathrm{m}$ / s were evaluated as a progressive motil, and spermatozoa with VAP 50 $\mu \mathrm{m} / \mathrm{s}$ were classified as rapid. The motility parameters were expressed in percentage units. Freezability values $(\Delta)$ were defined as the loss of motility due to the cryopreservation and it was calculated as the difference of percentage between the initial fresh motility and postthaw motility.

\section{Statistical Analysis}

The differences among the groups regarding Motility and Post-thaw motility were compared by using parametric ANOVA test. P-values, less than 0.05 were considered significant. Data comparison pertaining to the rest of the parameters were analyzed by non-parametrical Kruskal-Wallis test.

Before performing the statistical analysis, data were examined with Shapiro-Wilk test for normality and with Levene test for homogeneity of variances as parametric test assumptions. Descriptive statistics for each variable were calculated and presented as standard deviation. All data were analyzed using MIXED procedure of SPSS (V22.0; SPSS Inc., Chicago, IL, USA). The effect of group, bulls and their interaction on freezing, straw, post-thaw motility, ejaculate, concentration, total motil- 
ity $\%$, Concentration/ejaculate and freezing/CASA motility were analyzed using following model with repeated measures:

$$
Y_{i j k}=\mu+G_{i}+B_{j}+(G \times B)_{i j}+e_{i j k}
$$

Where, $Y_{i j k}$, dependent variable; $\mu$, overall mean; $G_{i}$, effect of the group ( $i=F M-0, F M-1$ and $\left.F M-2\right) ; B_{j}$, effect of bulls $\left({ }_{j}=-10,3\right.$ and $\left.10 \mathrm{~d}\right) ;(G \times B)_{i j}$, interaction between group $\mathrm{i}$ and bulls $\mathrm{j}$; and $\mathrm{e}_{\mathrm{ijk}}$, residual error.

Group, bulls and their interaction were assessed as a fixed effect. $P<0.001$ was considered as significant in all analyses. When a significant difference was revealed, any significant terms were compared by Simple effect analysis with Bonferroni adjustment.

\section{Results}

The initial sperm motility was similar among the three groups of FM ( $P>0.05)$ and although there were no significant differences, the post-thaw motility tended to improve with the increased number of FM. Besides, statistically significant differences were detected in volume and concentration $(P<0.001)$. With the increase of sexual stimulation through the FM, there was an elevated answer at the collection time and the highest concentration was obtained in FM- 2 group as $1326.7 \pm 365.07 \times$ $10^{6}$ sperm $/ \mathrm{mL}(P<0.001)$. Despite the increased concentration, reduced volumes were observed in false mounted bulls (FM- 1 and FM- 2) regardless of the number of the FM activity (Table 1). Similarly, total sperm output in the pooled ejaculates was statistically higher in double FM group ( $8826.3 \pm 4242.48 \times 10^{6}$ sperm) than in single FM group (7236.6 $\pm 3204.76 \times 10^{6}$ sperm) $(P<0.05)$. In accord with the concentration, the highest number of straws per pooled ejaculates were obtained in FM- 2 group $(396.0 \pm 183.63)(P<0.05)$. The increase in both the concentration and the number of produced straws was more evident in the samples, which initially had the lower values with the lack of FM.

Table 1. The relationship between the number of false mounting and semen parameters.

\begin{tabular}{lcccc}
\hline & \multicolumn{4}{c}{ Number of False Mounting } \\
\cline { 2 - 5 } Semen Parameters & $0(\mathrm{n}=60)$ & $1(\mathrm{n}=60)$ & $2(\mathrm{n}=60)$ & P-value \\
\hline Mean ejaculate volume $(\mathrm{ml})$ & $4.10 \pm 1.13^{\mathrm{a}}$ & $3.29 \pm 1.24^{\mathrm{b}}$ & $3.38 \pm 1.27^{\mathrm{b}}$ & $<0.001$ \\
\hline Concentration $\left(\times 10^{6}\right.$ sperm/ml) & $1013.68 \pm 329.26^{\mathrm{a}}$ & $1124.73 \pm 382.01^{\mathrm{a}}$ & $1326.70 \pm 365.07^{\mathrm{b}}$ & $<0.001$ \\
Total sperm output of pooled ejaculates (x $10^{6}$ sperm) & $8026.30 \pm 2685.53^{\text {ab }}$ & $7236.57 \pm 3204.76^{\mathrm{a}}$ & $8826.32 \pm 4242.48^{\mathrm{b}}$ & 0.043 \\
\hline Fresh motility (\%) & $83.00 \pm 3.59$ & $82.75 \pm 2.83$ & $83.92 \pm 3.58$ & 0.136 \\
\hline Post-thaw motility (\%) & $59.75 \pm 10.80$ & $61.08 \pm 8.86$ & $63.97 \pm 10.56$ & 0.068 \\
\hline Freezability $(\Delta)$ & $23.25 \pm 11.10$ & $21.67 \pm 8.74$ & $19.95 \pm 10.67$ & 0.212 \\
\hline Total number of straws / pooled ejaculates & $318.00 \pm 108.34^{\mathrm{b}}$ & $302.00 \pm 131.00^{\mathrm{b}}$ & $396.00 \pm 183.63^{\mathrm{a}}$ & 0.004 \\
\hline
\end{tabular}

a,b Mean values \pm standard deviations within a row with different superscripts differ significantly at $P<0.05$.

Additionally, with the lack of FM activity, the volume of semen was lower in the consecutive second ejaculates than the first ones (Table 2). However, in FM groups, the volume was either equal between the ejaculates (FM- 2), or higher volumes were obtained in the second ejaculation (FM- 1). Contrary to these findings, overall, the mean volume tended to decrease by $0.2 \mathrm{~mL}$ in the second ejaculates, as it was observed similarly in each breed.

Table 2. Volumes of consecutive ejaculates regarding the different breeds and the number of false mounting

\begin{tabular}{|c|c|c|c|c|c|c|c|c|}
\hline \multirow{2}{*}{\multicolumn{2}{|c|}{$\begin{array}{l}\text { Total and Mean Volumes of } \\
\text { Consecutive Ejaculates } \\
(\mathrm{ml})\end{array}$}} & \multicolumn{3}{|c|}{ Breed of the Bulls } & \multicolumn{3}{|c|}{ Number of False Mounting } & \multirow{2}{*}{$\begin{array}{c}\text { Total } \\
(n=360)\end{array}$} \\
\hline & & $\begin{array}{c}\text { Simmental } \\
(n=180)\end{array}$ & $\begin{array}{c}\text { Brown Swiss } \\
(n=150)\end{array}$ & $\begin{array}{c}\text { Holstein } \\
(n=30)\end{array}$ & $\begin{array}{c}\text { FM } 0 \\
(n=120)\end{array}$ & $\begin{array}{c}\text { FM } 1 \\
(n=120)\end{array}$ & $\begin{array}{c}\text { FM } 2 \\
(n=120)\end{array}$ & \\
\hline \multirow{4}{*}{$1^{\text {st }}$ Ejaculate } & Mean \pm SD & $3.8 \pm 1.72$ & $3.5 \pm 1.43$ & $4.0 \pm 1.96$ & $4.5 \pm 2.26$ & $3.1 \pm 1.40$ & $3.4 \pm 1.53$ & $3.7 \pm 1.63$ \\
\hline & Minimum & 1.0 & 1.0 & 1.0 & 2.0 & 1.0 & 1.0 & 1.0 \\
\hline & Maximum & 8.5 & 9.0 & 8.0 & 9.0 & 8.0 & 8.0 & 9.0 \\
\hline & Total & 343.3 & 260.0 & 60.0 & 271.8 & 187.5 & 204.0 & 663.3 \\
\hline \multirow{4}{*}{$2^{\text {nd }}$ Ejaculate } & Mean \pm SD & $3.6 \pm 1.59$ & $3.3 \pm 1.08$ & $3.8 \pm 1.15$ & $3.7 \pm 1.13$ & $3.5 \pm 1.47$ & $3.4 \pm 1.48$ & $3.5 \pm 1.37$ \\
\hline & Minimum & 0.0 & 2.0 & 2.0 & 2.0 & 1.0 & 0.0 & 0.0 \\
\hline & Maximum & 8.0 & 7.0 & 6.0 & 7.0 & 8.0 & 8.0 & 8.0 \\
\hline & Total & 326.0 & 245.0 & 57.3 & 219.8 & 207.5 & 201.0 & 628.3 \\
\hline
\end{tabular}


Apart from that, the effect of the number of FM on sperm characteristics was analyzed individually for each of twelve bulls and in general, double FM resulted in improved post-thaw motility and thereby the freezability $(P<0.001)$, although, in one bull, a single FM was ad- equate to increase these values, while in another one, double FM led to a decrease in both of these parameters (Table 3). When the effect of individualism was neglected, the increase of post-thaw motility in FM groups were statistically insignificant ( $P>0.05)$.

Table 3. The interaction between the individual bulls and the number of false mounting on post-thaw motility and freezability of sperm

\begin{tabular}{|c|c|c|c|c|c|c|c|c|c|c|c|c|c|c|c|c|c|c|}
\hline \multirow[b]{2}{*}{ Parameters } & \multirow{2}{*}{$\begin{array}{c}\text { Number } \\
\text { of FM }\end{array}$} & \multicolumn{12}{|c|}{ Bull } & \multirow[b]{2}{*}{ SEM } & \multirow{2}{*}{$\begin{array}{c}\text { Estimated } \\
\text { Marginal } \\
\text { Means }\end{array}$} & \multicolumn{3}{|c|}{ P-value } \\
\hline & & 1 & 2 & 3 & 4 & 5 & 6 & 7 & 8 & 9 & 10 & 11 & 12 & & & $\begin{array}{c}\text { Number } \\
\text { of FM }\end{array}$ & Bull & $\begin{array}{l}\text { FM * } \\
\text { Bull }\end{array}$ \\
\hline \multirow{3}{*}{$\begin{array}{l}\text { Post-thaw motility } \\
\text { (\%) }\end{array}$} & $\mathrm{FM}-0$ & $68.00^{\mathrm{a}}$ & $44.60^{d}$ & $43.00^{\mathrm{d} . \mathrm{B}}$ & $54.20^{\text {bcd. } B}$ & $57.40^{\mathrm{abc} . \mathrm{B}}$ & $63.20^{\text {abc.A }}$ & $65.80^{\mathrm{ab}}$ & $62.40^{\mathrm{abc}}$ & $67.20^{\text {ab.AB }}$ & $31.00^{\mathrm{a}}$ & $50.60^{\text {cd. } B}$ & $69.60^{\mathrm{a}}$ & \multirow{3}{*}{2.83} & $59.75 \pm 0.82$ & \multirow{4}{*}{0.001} & \multirow{4}{*}{$<0.001$} & \multirow{4}{*}{$<0.001$} \\
\hline & FM-1 & $68.60^{a}$ & $52.60^{\mathrm{b}}$ & $57.60^{\mathrm{ab} . \mathrm{A}}$ & $53.80^{\text {b.B }}$ & $61.20^{\mathrm{ab} . \mathrm{AB}}$ & $57.60^{\text {ab.AB }}$ & ${ }^{\mathrm{B}} 61.00^{\mathrm{ab}}$ & $59.40^{\mathrm{ab}}$ & $61.20^{\text {ab. }}$ & $64.60^{\mathrm{ab}}$ & $70.60^{\mathrm{a} . \mathrm{A}}$ & $64.80^{\mathrm{ab}}$ & & $61.08 \pm 0.82$ & & & \\
\hline & $\mathrm{FM}-2$ & $74.20^{\mathrm{a}}$ & $52.40^{b c}$ & $49.60^{\mathrm{b} . \mathrm{AB}}$ & $73.00^{\mathrm{a} A \mathrm{~A}}$ & $70.80^{\mathrm{a} . \mathrm{A}}$ & $51.40^{\text {bc. } B}$ & $63.80^{\mathrm{ac}}$ & $68.00^{\mathrm{a}}$ & $71.00^{\mathrm{a} . \mathrm{A}}$ & $65.20^{\mathrm{ac}}$ & $67.60^{\mathrm{a} . \mathrm{A}}$ & $60.60^{\mathrm{ab}}$ & & $63.97 \pm 0.82$ & & & \\
\hline Estimated Marginal & Means & 70.27 & 49.87 & 50.07 & 60.33 & 63.13 & 57.40 & 63.53 & 63.27 & 66.47 & 66.93 & 62.93 & 65.00 & 1.63 & & & & \\
\hline \multirow{3}{*}{ Freezability $(\Delta)$} & FM-0 & $14.00^{\circ}$ & $37.40^{\mathrm{a}}$ & $37.00^{\mathrm{a} . \mathrm{A}}$ & $29.80^{\text {ab.A }}$ & $24.60^{\mathrm{abc} . \mathrm{A}}$ & $19.80^{\text {bc. }}$ & $19.20^{\mathrm{bc}}$ & $19.60^{\mathrm{bc}}$ & $18.80^{\text {bc.AB }}$ & $10.00^{c}$ & $35.40^{\mathrm{a} . \mathrm{A}}$ & $13.40^{\mathrm{c} . \mathrm{B}}$ & & $23.25 \pm 0.89$ & \multirow{4}{*}{0.034} & \multirow{4}{*}{$<0.001$} & \multirow{4}{*}{$<0.001$} \\
\hline & $\mathrm{FM}-1$ & $15.40^{\mathrm{ab}}$ & $28.40^{\mathrm{a}}$ & $24.40^{\mathrm{ab} . \mathrm{B}}$ & $28.20^{\mathrm{a} . \mathrm{A}}$ & $21.80^{\text {ab.A }}$ & $23.40^{\text {ab.AB }}$ & ${ }^{8} 25.00^{\mathrm{ab}}$ & $23.60^{\mathrm{ab}}$ & $21.80^{\text {ab. } A}$ & $18.40^{\mathrm{ab}}$ & $13.40^{\text {ab. } B}$ & $16.20^{\text {ab.AB }}$ & \multirow[t]{2}{*}{3.08} & $21.67 \pm 0.89$ & & & \\
\hline & $\mathrm{FM}-2$ & $12.80^{\mathrm{b}}$ & $29.60^{\mathrm{a}}$ & $31.40^{\mathrm{a} . \mathrm{AB}}$ & $10.00^{b .8}$ & $13.20^{\mathrm{b} . \mathrm{B}}$ & $32.60^{\mathrm{a} . \mathrm{A}}$ & $22.20^{\mathrm{ab}}$ & $14.00^{\mathrm{b}}$ & $11.00^{\mathrm{b} . \mathrm{B}}$ & $17.80^{\mathrm{ab}}$ & $20.40^{\text {ab. }}$ & $24.40^{\mathrm{ab} \cdot \mathrm{A}}$ & & $19.95 \pm 0.89$ & & & \\
\hline \multicolumn{2}{|c|}{ Estimated Marginal Means } & 14.07 & 31.80 & 30.93 & 22.67 & 19.87 & 25.27 & 22.13 & 19.07 & 17.20 & 15.40 & 23.07 & 18.00 & \multicolumn{2}{|l|}{1.78} & & & \\
\hline
\end{tabular}

$a, b, c, d$ Mean values within a row with different superscripts differ significantly at $P<0.001$

$A, B$ Mean values within a column with different superscripts differ significantly at $P<0.001$

\section{Discussion}

The false mounting is a process that allows the bull to mount on another bull for a limited period, before the actual ejaculation occurs. In the present study, the effect of the number of FM on spermatological parameters were evaluated by allowing the bulls to false mount once, twice or none at all, prior to the semen collection and as a result, sperm quality was enhanced significantly in double FM group, especially with respect to the concentration and post-thaw motility of spermatozoa.

False mounting is determined as the most efficient method for sexual preparation [2, 30], particularly since it indicates the sexual arousal clearly. In dairy bulls, the recommended procedure for sexual preparation is one false mount followed by two minutes of restraint, which is followed by two additional false mounts before each ejaculation. On the other hand, the response of beef bulls to FM and/or active restraint was either indifferent [11] or resulted with a minimal increase (3 FM) when repeated before the second collection [2]. Although some researches have tested the effect of higher numbers of FM activity, in the present study, this approach was not preferred due to the increased risk of bulls to get injured with the increased numbers of mounting attempts and dismounting $[5,13,30]$. Usually, bull-to-bull (teaser) or bull-to-phantom stimulations are used for sperm collection in Al Centres. In the present study, teaser stimulation was preferred for sperm collection.

In the current study, highest concentration was obtained in FM- 2 group. In spite of the increased concentration, reduced volumes were observed in false mounted animal groups (FM- 1 and FM- 2). In earlier researc- hes, "the booster" effect of FM on sperm output of bulls has been studied by several researchers $[2,4,14]$. However, these studies were conducted mainly on 1960s and updated results using the current available technology is needed. In lieu of subjective evaluation methods, in the present study, the results were obtained using objective analysers such as the CASA and spectrophotometer. The effect of FM on sperm output was investigated in other farm animals as well. In boars, the number of spermatozoa in the sperm rich fraction was greater $(P<0.05)$ when males were collected after a false mount [20]. On the contrary, in stallion, an increase in the number of mounts resulted in increased volume and total sperm count together with reduced sperm concentration of the ejaculate [33]. Along with other hormones, these procedures can cause the release of oxytocin, which may result in the enhancement of sperm transport or emission from the extragonadal reserves [6, 32]. In an early study in dairy bulls, total sperm number of the ejaculate increased with the number of false mounts from 7.1 billion (with the lack of FM), up to 14.2 (with double FM) while with three FM, a decrease to 13.5 billion sperm was observed. Furthermore, total sperm number has reached to 15.1 billion owing to the addition of $5 \mathrm{~min}$ active restraint into this procedure [13]. Divergent from the present study, the increase in sperm output was mainly associated with the increase of semen volume than the increase of sperm concentration. In the present study, the reduced volumes of ejaculates in FM groups may link to the dripping of the excess secretion of the glands during the FM activity, since these secretions are physiologically aimed to clean the urethral duct prior to ejaculation. Generally, as a part of sexual preparation, 
partial erection, protrusion of the penis with dribbling of accessory fluid and repeated and persistent attempts of mounting are observed in bulls [16]. Apart from the number of FM, the duration of sexual preparation has also been associated with the semen quality. In bulls, shorter preparation periods that are less than 15 minutes, led to greater volumes of ejaculates $(P<0.05)$ [17], while in men, a significant positive correlation between the duration and sperm concentration $(t=2.13, \mathrm{P}<0.05)$ was obtained [25]. It is known that following the sexual stimulation, the rate of sperm transported into the excurrent ducts increases and thus it can be concluded as the underlying reason of the increased sperm concentration due the FM activity $[9,27]$. Furthermore, Hafez and Bouissou [18] stated that, bulls which have the lowest sperm output show the greatest improvements with pre-stimulation. The present study agrees with the statement since the increase in both the concentration and the number of produced straws with the FM effect were more evident in the samples, which initially have/ had the lower values than higher ones, in the collections with the lack of FM.

It is important to note that sexual preparation does not affect the sperm production. However, with the increase in the efficiency of ejaculation, it allows collecting the maximal daily sperm output via minimum number of ejaculations, thus, eliminates the requirement of higher frequency of ejaculations [5]. It is beneficial for the Al industry, because it reduces the total time required to collect and process the maximal quantity of semen for a given male. Ideally, Al centres follow the double collection technique in order to maximise the number of the straws produced, and thereby the profitability [28]. A maximum number of collections per bull would depend on the individual capacity of the bull. In the present study, the volume of an ejaculate ranged from 1.5 to $8 \mathrm{~mL}$ with double collection technique. Generally, the volume of first ejaculate is higher than the following consecutive ones $[21,29]$. Similarly, in the current study, a decrease was observed in the volume of second ejaculate in overall and each breed group, especially in FM0 group. However, in FM groups, the volume of second ejaculate was able to reach and exceed the first ones. The overall reduction in semen volume seems to be largely related to the short collection interval between consecutive ejaculates $[12,21]$. In the present study, this interval is prolonged due to FM activity and bulls could have adequate time for sexual preparation. Furthermore it has been stated that, the collection of multiple ejaculates on the same day did not affect the post-thaw motility, but the pre-freeze motility was reduced $(P<0.01)$ in Holstein bulls [21], whereas no significant difference was observed in Shorthorn-Zebu breed [23]. Although in general, second ejaculates are of less volume and sperm concentration, the collection of sequential ejaculates increases productivity per unit time, as more insemination doses can be obtained on a given day.
Even though the initial sperm motility was similar among the three groups of FM, on the individual bases, generally, double FM resulted in improved postthaw motility and thereby the freezability $(P<0.001)$, although, in one bull, a single FM was adequate to increase these values, while in another one, double FM has led to a decrease in both these parameters. Contrary to the positive influence of sexual preparation on sperm output, there is less evidence for its influence on sperm characteristics. However, few researchers have reported that the pre-coital stimulation and/or 'preparation' of bulls by false mounts and restraint, beyond that adequate for mounting and ejaculation have improved the motility and survival rate of the sperm as well as the conception rate $[3,9]$. The mechanism behind the improvement of post-thaw motility due to FM is unclear and still needs detailed research but it can be assumed that the increase of initial sperm concentration and the reduction in the volume led to the use of higher dilution rates during the sperm processing and in return, this could favour the post-thaw motility enhancement. Various researches have investigated the effect of concentration on post-thaw semen quality in ram [1, 19], buck [4] and stallion [22] and their result revealed that higher dilution and/or lower sperm concentration has led to enhancement of motility as well as intact plasma membrane and acrosome integrity. This effect may be linked with the release of reactive oxygen species from sperm cells into their surrounding medium due to the stress during the freeze-thaw process, can be alleviated owing to the use of higher dilution rates by lowering the concentration of these factors. Similarly, a study conducted on Norwegian Cattle bulls has revealed that sexual preparation beyond 15 minutes resulted with higher post-thaw motility without any significant differences in 60 -day non-return rates [17]. It can be concluded that various conditions such as frequency of collection, duration of sexual preparation and type of semen collection and the rate of dilution of the semen may have an influence on the harvested semen quality [35]. Besides, it has been stated that certain semen characteristics are more variable than others $[7,10,26,34,36]$.

According to our results, double FM activity before the semen collection increased the post-thaw motility and concentration of spermatozoa and therefore the number of straws produced. In conclusion, double FM is recommended as a method to increase the libido and sperm quality of bulls and Artificial Insemination centres could benefit from the double FM activity prior to semen collection. However, differences in the response of individuals should be kept in mind, and in order to obtain the maximum yield from each bull, it would be wise to initially test the individual responses of each bull and optimise the number of FM treatment accordingly.

\section{Acknowledgments}

The authors are thankful to, General Directorate of Agricultural Research and Policies (GDARP) and Inter- 
national Center for Livestock Research and Training, to provide the necessary animal material to carry out the research programme.

\section{Credit}

The pre-elaminary results were published in $8^{\text {th }} \mathrm{Na}$ tional Reproduction and Artificial Insemination Congress at 5-9 September, 2016, Antalya, Turkey

\section{References}

1. Akçay E, Kulaksız R, Daşkin A, Çebi Ç, Tekin K (2012). The effect of different dilution rates on post-thaw quality of ram semen frozen in two different egg-yolk free extenders. Slovenian Veterinary Research, 49(2): 97-102.

2. Almquist JO (1973). Effects of sexual preparation on sperm output, semen characteristics and sexual activity of beef bulls with a comparison to dairy bulls. Journal of Animal Science, 36(2): 331-336. DOI: 10.2527/jas1973.362331x.

3. Amann RP, Almquist JO (1976). Bull management to maximize sperm output. In: Proceedings of the 6th Technical Conference on Artificial Insemination and Reproduction, Columbia, Missouri, USA, pp. 1-10.

4. Anand, M, Yadav S, Kumar A, Vaswani S, Shukla P (2018). Effect of Dilution and Sperm Concentration on Post Thaw Semen Quality in Barbari Buck. Journal of Animal Research, 8(4): 587592.

5. Berndtson WE (2014). Sperm production and its harvest. In: Chenoweth PJ, Lorton SP (editors). Animal Andrology: Theories and Applications. $1^{\text {st }}$ edition Centre for Agriculture and Bioscience International (CABI), Wallingford Connecticut, pp. 11-33.

6. Berndtson WE, Igboeli G (1988). Spermatogenesis, sperm output and seminal quality of Holstein bulls electroejaculated after administration of oxytocin. Reproduction, 82(2): 467-475. DOI: 10.1530/jrf.0.0820467.

7. Bhakat M, Mohanty TK, Singh S, Gupta AK, Chakravarty AK, Singh P (2015). Influence of semen collector on semen characteristics of Murrah buffalo and Crossbred bulls. Adv. Anim. Vet. Sci, 3(4): 253-258.

8. Brito LF (2014). Applied Andrology in Cattle (Bos taurus). In: Chenoweth PJ, Lorton SP (editors). Animal Andrology: Theories and Applications. $1^{\text {st }}$ edition Centre for Agriculture and Bioscience International (CABI), Wallingford Connecticut, pp. 297-350.

9. Chenoweth PJ (1983). Examination of bulls for libido and breeding ability. The Veterinary Clinics of North America. Large Animal Practice, 5(1): 59-74. DOI: 10.1016/S01969846(17)30092-7.

10. Foote RH (1978). Factors influencing the quantity and quality of semen harvested from bulls, rams, boars and stallions, Journal of Animal Science, 47: 1-11.

11. Foster J, Almquist JO, Martig RC (1970). Reproductive capacity of beef bulls. IV. Changes in sexual behavior and semen characteristics among successive ejaculations. Journal of Animal Science, 30(2): 245-252. DOI: 10.2527/jas1970.302245x

12. Fuerst-Waltl B, Schwarzenbacher H, Perner C, Sölkner J (2006). Effects of age and environmental factors on semen production and semen quality of Austrian Simmental bulls. Animal Reproduction Science, 95(1-2): 27-37. DOI:10.1016/j.anireprosci.2005.09.002.
13. Hafs HD, Knisely R C, Desjardins C (1962). Sperm output of dairy bulls with varying degrees of sexual preparation. Journal of Dairy Science, 45(6): 788-793.

14. Hale EB, Almquist JO (1960). Relation of sexual behavior to germ cell output in farm animals. Journal of Dairy Science, 43(1): 145.

15. Katz LS, McDonald TJ (1992). Sexual behaviour of farm animals in reproduction in farm animals: Science, application and models. Theriogenology, (38): 240-254.

16. Kerruish BM (1955). The effect of sexual stimulation prior to service on the behaviour and conception rate of bulls. The British Journal of Animal Behaviour, 3(4): 125-130. DOI: 10.1016/S0950-5601(55)80049-4.

17. Kommisrud E, Andersen Berg K (1996). The influence of duration of sexual preparation on bovine semen characteristics and fertility rates. Reproduction in Domestic Animals, 31(2): 369-371. DOI: 10.1111/j.1439-0531.1996.tb00087.x.

18. Le Danvic C, Gérard O, Sellem E, Ponsart C, Chemineau P, Humblot P, Nagnan-Le Meillour P (2015). Enhancing bull sexual behavior using estrus-specific molecules identified in cow urine. Theriogenology, 83(9): 1381-1388.

19. Leahy T, Marti JI, Mendoza N, Perez-Pe R, Muino-Blanco T, et al. (2010). High pre-freezing dilution improves post-thaw function of ram spermatozoa. Animal Reproduction Science, 119: 137-46. DOI: 10.1016/j.anireprosci.2009.12.003.

20. Levis DG, Reicks DL (2005). Assessment of sexual behavior and effect of semen collection pen design and sexual stimulation of boars on behavior and sperm output-a review. Theriogenology, 63(2): 630-642. DOI: 10.1016/j.theriogenology.2004.09.037.

21. Murphy EM, Kelly AK, O'Meara C, Eivers B, Lonergan P, et al. (2018). Influence of bull age, ejaculate number, and season of collection on semen production and sperm motility parameters in Holstein Friesian bulls in a commercial artificial insemination centre. Journal of Animal Science, 96(6): 2408-2418. DOI: 10.1093/jas/sky130.

22. Nascimento J, Raphael CF, Andrade AFC, Celeghini ECC, Arruda RP (2008). Effect of sperm concentration and straw volume on motion characteristics and plasma, acrosomal and mitochondrial membranes of equine. Journal of Equine Veterinary Science, 28: 351-358.

23. Olurode SA, Sekoni VO, Oyenekan IO, Adetomiwa AS (2018). Effect of season on reproduction in west African Dwarf Bucks. Nigerian Veterinary Journal, 39(1): 35-44.

24. Petherick JC (2005). A review of some factors affecting the expression of libido in beef cattle, and individual bull and herd fertility. Applied Animal Behaviour Science, 90(3-4): 185-205. https://doi.org/10.1016/j.applanim.2004.08.021.

25. Pound N, Javed MH, Ruberto C, Shaikh MA, Del Valle AP (2002). Duration of sexual arousal predicts semen parameters for masturbatory ejaculates. Physiology and Behavior, 76(4-5): 685-689. DOI: 10.1016/S0031-9384(02)00803-X.

26. Prastowo $S$, Widyas N, Ratriyanto A, Kusuma MST, Dharmawan P, Setiawan IA, Bachtiar A (2019). November. Individual Variance Component of Fresh Semen Quality in Bali Cattle (Bos javanicus) Bull. In IOP Conference Series: Earth and Environmental Science 372: 1- 012025). IOP Publishing.

27. Prins GS, Zaneveld LJ (1980). Radiographic study of fluid transport in the rabbit vas deferens during sexual rest and after sexual activity. Journal of Reproduction and Fertility, (58): 311-319. 
28. Rouge M (2002). Semen Collection from Bulls. Pathophysiology of the Reproductive System, Colorado State University. Accessed June, 2019.

29. Sankhi S, Sapkota KR, Regmi B (2019). Effect of age and frequency of collection on quality of Jersey bulls semen at National Livestock Breeding Center (NLBC), Nepal. International Journal of Applied Sciences and Biotechnology, 7(1): 88-95. https:// doi.org/10.3126/ijasbt.v7i1.23312.

30. Schenk JL (2018). Principles of maximizing bull semen production at genetic centres. Animal, 12(1): 142-147. DOI: 10.1017/ S1751731118000472.

31. Senger PL (2012). Reproductive Behavior. In: Senger PL (editor). Pathways to Pregnancy and Parturition. $3^{\text {rd }}$ ed. Current Concepts Inc., Washington State University Research and Technology Park, USA, pp. 240-265.

32. Sharma OP, Hays RL (1973). Release of an oxytocic substance following genital stimulation in bulls. Reproduction, 35(2): 359-362. DOI: 10.1530/jrf.0.0350359.
33. Sieme H, Katila T, Klug E (2004). Effect of semen collection practices on sperm characteristics before and after storage and on fertility of stallions. Theriogenology, 61(4): 769-784. DOI: 10.1016/s0093-691x(03)00251-6.

34. Singh S, Bhakat M, Mohanty TK, Kumar A, Gupta AK, Chakravarty AK, Singh P (2015). Sexual behavior and its relationship with semen quality parameters in Sahiwal breeding bulls. Veterinary world, 8(6): 745.

35. Swelum, AAA, Saadeldin IM, Zaher HA, Alsharifi, SA, Alowaimer AN (2017). Effect of sexual excitation on testosterone and nitric oxide levels of water buffalo bulls (Bubalus bubalis) with different categories of sexual behavior and their correlation with each other. Animal reproduction science, 181: 151-158.

36. Tekin K, Parildar, ÖO, Bastan I, Şahin D, Stelletta C, Daskin A (2018). Sexuel deactivity on spermatological parameters in Angora Goat. International symposium of Erdemli, Mersin. Page: 238. 